\title{
High-Flow Nasal Cannula and COVID-19: A Clinical Review
}

\author{
Claudia Crimi, Paola Pierucci, Teresa Renda, Lara Pisani, and Annalisa Carlucci
}

\author{
Introduction \\ Methods \\ Rationale and Physiologic Effects \\ HFNC and COVID-19 Pneumonia \\ Advantages and Disadvantages Compared With Standard Oxygen \\ Advantages and Disadvantages Compared With NIV and CPAP \\ HFNC Initiation: Setting Considerations \\ Clinical Application \\ Advantages of HFNC Combined With Prone Positioning \\ Aerosol-Generating Risk \\ HFNC Use in COVID-19 \\ Clinical Implications, Critical Issues, and Limitations \\ Summary
}

\begin{abstract}
During the coronavirus disease 2019 (COVID-19) pandemic, noninvasive respiratory support has played a central role in managing patients affected by moderate-to-severe acute hypoxemic respiratory failure, despite inadequate scientific evidence to support its usage. High-flow nasal cannula (HFNC) treatment has gained popularity because of its effectiveness in delivering a high fraction of humidified oxygen, which improves ventilatory efficiency and the respiratory pattern, as well as its reported high tolerability, ease of use, and application outside of ICUs. Nevertheless, the risk of infection transmission to health-care workers has raised some concerns about its use in the first wave of the pandemic outbreak, with controversial recommendations provided by different scientific societies. This narrative review provides an overview of the recent evidence on the physiologic rationale, risks, and benefits of using HFNC instead of conventional oxygen therapy and other types of noninvasive respiratory support devices, such as continuous positive airway pressure and noninvasive ventilation in patients affected by COVID-19 pneumonia with associated acute hypoxemic respiratory failure. It also summarizes the available evidence with regard to the clinical use of HFNC during the current pandemic and its reported outcomes, and highlights the risks of bioaerosol dispersion associated with HFNC use. Key words: High-flow nasal cannula; COVID-19; SARS-CoV-2; acute hypoxemic respiratory failure; ARDS. [Respir Care 2022;67(2):227-240. (C) 2022 Daedalus Enterprises]
\end{abstract}

\section{Introduction}

The coronavirus disease 2019 (COVID-19) pandemic has impacted the health-care system and resulted in an unprecedented number of patients who are critically ill with moderate-to-severe acute hypoxemic respiratory failure, which requires a high $\mathrm{F}_{\mathrm{IO}_{2}}$, noninvasive respiratory support or a rapid escalation to endotracheal intubation (ETI), and invasive mechanical ventilation. Although the best option for noninvasive respiratory support systems in the management of acute hypoxemic respiratory failure is still a matter of debate, high flows nasal cannula (HFNC) has emerged as an effective and well-tolerated respiratory support technique in various clinical scenarios. ${ }^{1,2}$ Furthermore, by 
providing high-flows of oxygen-enriched gas with lowlevel PEEP, HFNC has been suggested as an alternative to conventional oxygen therapy or noninvasive ventilation (NIV) in a well-selected group of patients with acute hypoxemic respiratory failure. ${ }^{1}$ Similarly, HFNC could be a valuable and feasible treatment option for patients with COVID-19 pneumonia, with remarkable clinical advantages. Its easy setup allows for rapid training, even for nonexpert personnel with heterogeneous backgrounds. ${ }^{3}$ Thus, its implementation in a non-ICU setting ${ }^{4}$ might be crucial for countries and health-care systems with shrinking critical care and invasive ventilation resources. ${ }^{5,6}$

Despite the theoretical physiologic rationale and HFNC's potential clinical usefulness, the use of HFNC was limited and variable during the first wave of the pandemic. ${ }^{4,7}$ In addition, the application of high gas flows initially raised doubts and controversies about the safety of the device in terms of aerosolization of droplets and infection transmission. ${ }^{6}$ Here, we summarized the role of HFNC in patients affected by COVID-19-associated acute hypoxemic respiratory failure, the rationale for its use, the advantages of HFNC over standard oxygen and other types of noninvasive respiratory support devices (CPAP and NIV), the evidence for its aerosol generation and clinical applications, and recommendations for its use during the pandemic.

\section{Methods}

MEDLINE and PubMed were searched to identify observational studies, randomized clinical trials (RCT), metaanalyses, and clinical practice guidelines by using the search terms: "(high-flow nasal cannula or HFNC) and (COVID-19

Dr Crimi is affiliated with the Respiratory Medicine Unit, "PoliclinicoVittorio Emanuele-San Marco," University Hospital, Catania, Italy. Dr Pierucci is affiliated with the Respiratory Medicine Unit, Policlinico "Aldo Moro" University Hospital, Bari, Italy. Dr Renda is affiliated with the Respiratory and Critical Care Unit, Cardio-thoracic and Vascular Department, Careggi Teaching Hospital, Florence, Italy. Dr Pisani is affiliated with the Respiratory and Critical Care Unit, IRCCS Azienda Ospedaliero Universitaria di Bologna, University Hospital Sant'Orsola-Malpighi, Bologna, Italy. Dr Pisani is affiliated with the Department of Clinical, Integrated and Experimental Medicine, Alma Mater Studiorum University, Bologna, Italy. Dr Carlucci is affiliated with the Department of Medicine and Surgery, Università Insubria, Varese-Como, Italy. Dr Carlucci is affiliated with the Pulmonary Rehabilitation Unit, Istituti Clinici Scientifici Maugeri, Pavia, Italy.

The authors have disclosed no conflicts of interest.

Supplementary material related to this paper is available at http://www. rcjournal.com.

Correspondence: Claudia Crimi MD PhD, Respiratory Medicine Unit, A. O.U. "Policlinico-Vittorio Emanuele-San Marco," Via S. Sofia, 78, 95123, Catania, Italy. E-mail: dott.claudiacrimi@gmail.com.

DOI: $10.4187 /$ respcare.09056 or coronavirus)." To identify ongoing clinical trials, we sought trials registered to study HFNC treatment for COVID19 and severe acute respiratory syndrome coronavirus 2 (SARS-CoV-2) at https://clinicaltrials.gov. The last update of the search was performed in January 2021. A single reviewer (CC) screened all potential references for inclusion.

\section{Rationale and Physiologic Effects}

The main physiologic effects of HFNC are summarized in Table 1. These findings were obtained from the bench and from the clinical studies performed in healthy volunteers ${ }^{8-12}$ and heterogeneous groups of subjects affected by acute respiratory failure. ${ }^{13-20}$ When considering the rationale mentioned above, HFNC might have a potential role in the clinical management of acute hypoxemic respiratory failure associated with COVID-19 pneumonia.

\section{HFNC and COVID-19 Pneumonia}

HFNC might have potential clinical benefits for patients when provided early in the course of acute hypoxemic respiratory failure., ${ }^{9,21}$ Evidence that emerged during the COVID-19 pandemic showed that the application of HFNC was feasible to treat patients with acute hypoxemic respiratory failure due to COVID-19 in non-ICU settings or for patients with a poorer prognosis who have been denied admission to the ICU. ${ }^{4,23,24}$ Many centers have reported their experiences in observational studies, as shown in Table 2. To date, there is a lack of robust data from RCTs on the timely use of HFNC in COVID-19-associated acute hypoxemic respiratory failure. Nevertheless, a few RCTs are ongoing and registered in trial registry databases, as shown in Table 3.

\section{Advantages and Disadvantages Compared With Standard Oxygen}

HFNC decreased the need for intubation or escalation of treatment compared with standard oxygen in patients without COVID-19 who were critically ill and with acute hypoxemic respiratory failure, and recent clinical practice guidelines strongly recommended its use ${ }^{1}$; similarly, HFNC performs better than standard oxygen in COVID-19 settings. ${ }^{6,25}$ This beneficial effect is probably due to its ability to more adequately match patients' respiratory flow demands, reduce inspiratory effort, and decrease the risk of patients' selfinflicted lung injury, ${ }^{26}$ which may have important implications for the management of the heterogeneous pulmonary manifestations of patients with COVID-19. ${ }^{27}$ Furthermore, the heat and humidification delivered by HFNC help to maintain hydration and mobilize secretions, which positively affect the mucus hypersecretion of patients with COVID-19, ${ }^{28-31}$ even if the delivered heated air may initially bother the patient. ${ }^{32}$ 
Table 1. Physiological Effects of High-Flow Nasal Cannula

\begin{tabular}{|c|c|c|}
\hline Effects & Mechanisms & Reference No. \\
\hline 1. Effective oxygenator & $\begin{array}{l}\text { The delivery of high flow allows matching patients' inspiratory } \\
\text { peak flow, even in patients generating high inspiratory peak } \\
\text { flow, avoiding dilution with room air }\end{array}$ & 8 \\
\hline 2. Secretion mobilization & $\begin{array}{l}\text { The warmed and humidified air preserves and optimizes } \\
\text { mucociliary function and reduces mucus viscosity }\end{array}$ & 12,14 \\
\hline 3. Reduction of work of breathing & $\begin{array}{l}\text { A flow-dependent improvement of ventilatory efficiency and } \\
\text { respiratory mechanics and consequent reduction of the } \\
\text { breathing frequency and inspiratory effort }\end{array}$ & $15,16,17$ \\
\hline 4. Increase of PEEP and end-expiratory lung volume & $\begin{array}{l}\text { A flow-dependent increase in expiratory resistance generates a } \\
\text { PEEP in the airways, proportional to the set flow, increasing } \\
\text { end-expiratory lung volumes }\end{array}$ & $8,9,10,11,18,19$ \\
\hline 5. Reduction of inspiratory resistance & $\begin{array}{l}\text { A minimum positive pressure is still present at the start of } \\
\text { inspiration (driving pressure), which allows a decrease in } \\
\text { inspiratory resistance of the upper airways }\end{array}$ & 19 \\
\hline 6. Clearance of anatomic dead space in upper airways & $\begin{array}{l}\text { The high gas flow flushes the nasopharynx, replacing the expired } \\
\mathrm{CO}_{2} \text {-rich gas of the upper airways with fresh air enriched with } \\
\text { oxygen (reservoir effect) }\end{array}$ & 20 \\
\hline
\end{tabular}

\section{Advantages and Disadvantages Compared With NIV and CPAP}

Current guidelines do not recommend the routine use of NIV in patients with de novo acute hypoxemic respiratory failure without previous chronic respiratory and cardiac disease, ${ }^{33}$ which suggests that an NIV trial might be attempted only by an experienced clinical team in a "protective" environment, such as an ICU. Moreover, a lung-protective strategy required to avoid the triggering and/or worsening of ventilator-induced lung injury is challenging to achieve in most patients who receive NIV for de novo acute hypoxemic respiratory failure. ${ }^{34}$ The patient's high inspiratory effort contributes to generating a large tidal volume despite the relatively low inspiratory pressure during NIV. Thus, lung injury can be caused by the ventilator, the patient's own breathing, or both, and can be predicted by a high tidal volume $(>9.5 \mathrm{~mL} / \mathrm{kg})^{35}$ and high inspiratory effort as assessed with an esophageal pressure swing. ${ }^{36}$ A recent study showed better outcomes and decreased risk of death when using helmet NIV than mask NIV in patients with $\operatorname{ARDS}^{37}$ due to the ability of the helmet to keep higher PEEP levels without worsening leaks. Nevertheless, a physiologic study showed that, although the helmet improved oxygenation compared with HFNC, the patients with low inspiratory effort on HFNC increased their transpulmonary pressure if shifted onto helmet NIV. ${ }^{38}$ Indeed, NIV intolerance is common in patients with acute respiratory failure, and it is a determinant of NIV failure, ${ }^{39}$ which is associated with a worse prognosis and increased mortality. ${ }^{33}$

In this regard, HFNC is generally better tolerated than NIV. ${ }^{40}$ Therefore, the treatment can be maintained for several hours with less risk of skin breakdown, ${ }^{41}$ which avoids alveolar de-recruitment and oxygen reduction, which typically occur during NIV interruption. Moreover, HFNC can reduce inspiratory effort ${ }^{42}$ similar to NIV, without the downsizes and concerns of air leakage, patient-ventilator synchrony, and the need of sedation, ${ }^{43}$ which offers a good balance between adequate oxygenation and comfort. ${ }^{44}$ However, unlike NIV, HFNC cannot deliver high PEEP levels. In addition, it is crucial to consider amid a pandemic that HFNC is easier to set up and implement than NIV. ${ }^{3}$ Therefore, HFNC success is less dependent on the expertise of the team, as required for $\mathrm{NIV}^{3}$ to avoid asynchronies, leaks, and intolerance, ${ }^{45}$ even if adequate staff training is essential to ensure proper use of the technique and patient safety. Furthermore, the soft and easy-to-fit HFNC interface creates less burden on the patient's face, and it is more "patient friendly," which allows the patient to be unimpeded while speaking, coughing, or eating meals. ${ }^{46}$ Indeed, in critical-care resource-limited settings, HFNC could represent an alternative strategy to NIV to support patients who are hypoxemic with comfort care only, ,3,47,48 $^{\text {as usu- }}$ ally happens in a non-pandemic time. ${ }^{49}$

\section{HFNC Initiation: Setting Considerations}

The amount of flow that should be used for patients with COVID-19 is still a matter of debate due to the lack of RCTs, and the published evidence shows significant variability in the settings used (Table 2). However, evidence from observational studies suggests that higher flows, between 50 and $60 \mathrm{~L} / \mathrm{min}$, are mainly used, similar to the scientific evidence on non-COVID-19 acute hypoxemic respiratory failure, ${ }^{21,50-55}$ according to the described flow- 


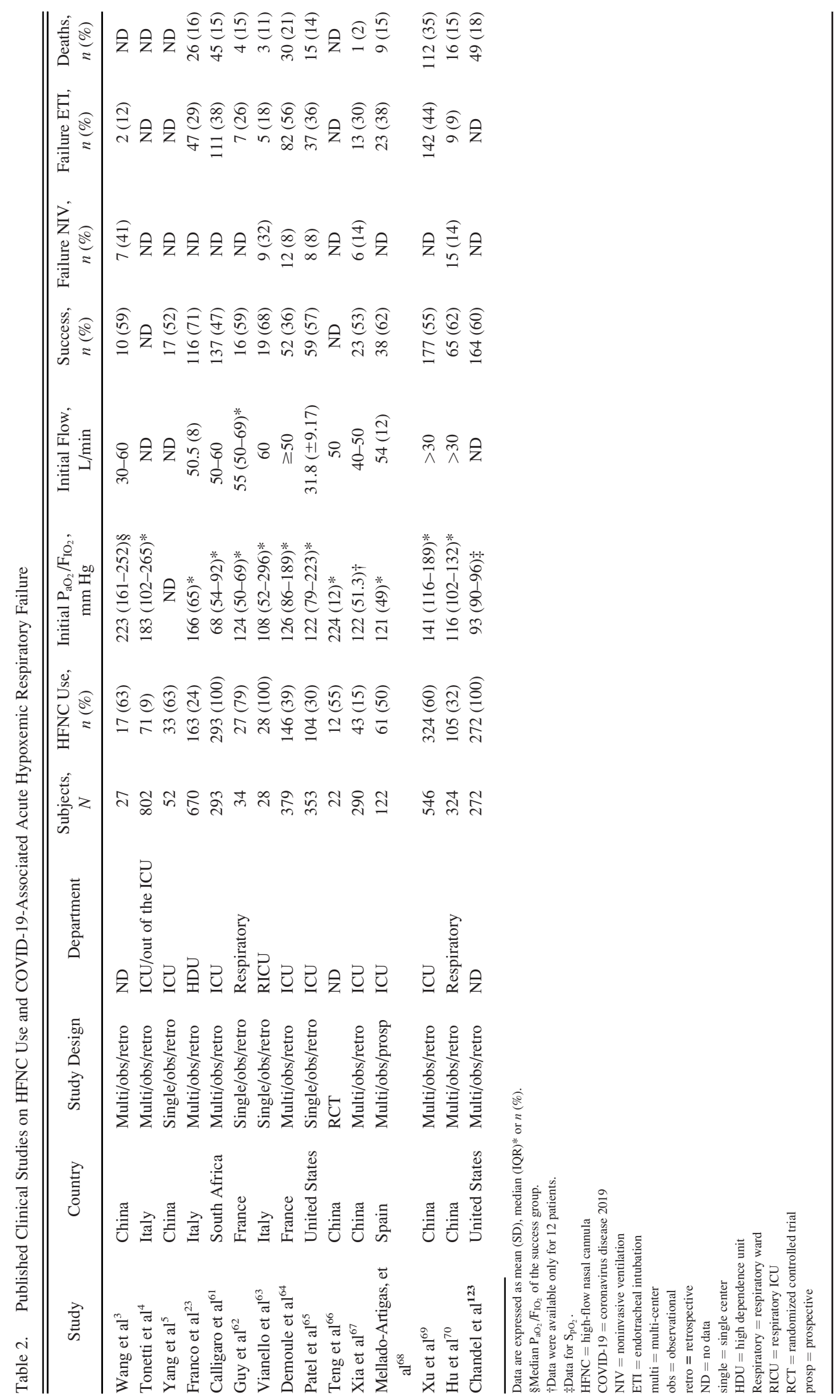




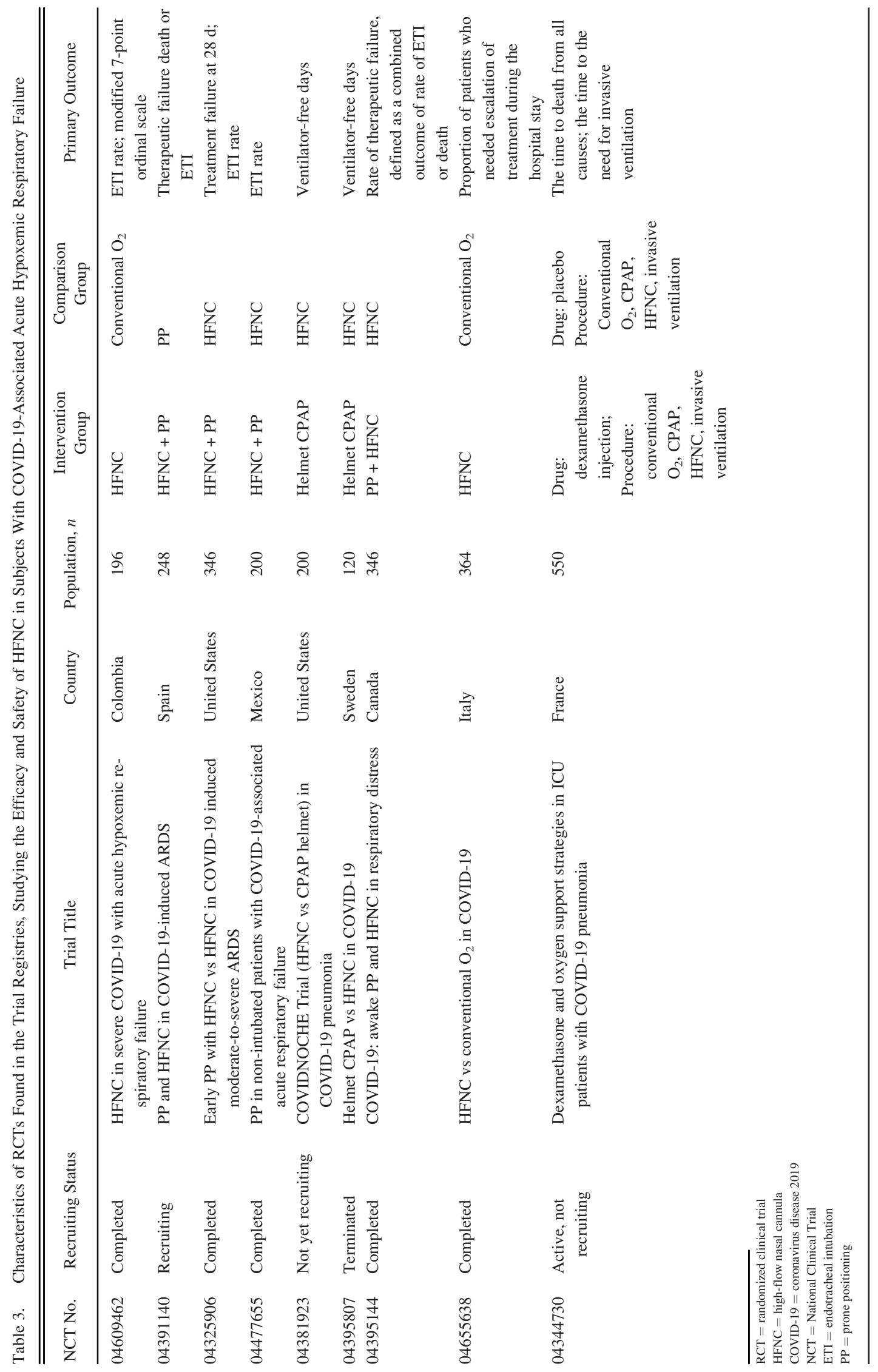


dependent physiologic effects of HFNC, and data from systematic reviews, which reported a flow of $>45 \mathrm{~L} / \mathrm{min}$ in most of the included studies. ${ }^{56-59}$ Moreover, a recent bench study showed that HFNC set at a higher flow and larger cannula size might generate higher positive pressure. ${ }^{60}$

\section{Clinical Application}

HFNC has been reported as a valuable therapeutic resource during the pandemic to ration ICU resources (both beds and ventilators), ${ }^{4,61,62}$ and its use has been widely and heterogeneously reported in the literature..$^{3-5,23,61-70}$ Thus, in resourceconstrained health systems, HFNC was feasible for successfully treating severe COVID-19 acute hypoxemic respiratory failure in almost half of those who received it, with no need for invasive mechanical ventilation, in a non-ICU environment when using an affordable pulse oximetry-based monitoring. ${ }^{61}$ In a retrospective observational study, Wang et al ${ }^{3}$ reported the use of HFNC as primary respiratory support in 17 subjects hospitalized with COVID-19 pneumonia (63\%), with NIV and invasive ventilation in only $9(33 \%)$ and 1 subject (4\%), respectively. Interestingly, among the 17 subjects treated with $\mathrm{HFNC}, 7(41 \%)$ with lower $\mathrm{P}_{\mathrm{aO}_{2}} / \mathrm{F}_{\mathrm{IO}_{2}}$ switched to NIV due to HFNC failure. ${ }^{3}$ However, only $29 \%$ of the subjects received intubation after NIV escalation. ${ }^{3}$ Similarly, an early report from the Italian experience during the first wave of the pandemic reported the use of HFNC in 28 subjects admitted to a respiratory intermediate care unit with a success rate of $67.8 \%$ and a lower initial $\mathrm{P}_{\mathrm{aO}} / \mathrm{F}_{\mathrm{IO}_{2}}$ associated with treatment failure. ${ }^{63}$

A recent multi-center retrospective study demonstrated the feasibility of noninvasive respiratory support application to treat COVID-19-related acute hypoxemic respiratory failure outside the ICU and showed that HFNC was used in 163 of 671 subjects $(24.3 \%$ ), of whom, $71 \%$ avoided intubation. ${ }^{23}$ Although limited by the study design, interestingly, no significant difference in the primary outcomes was shown compared with CPAP and NIV (intubation rate of $29 \%$ for HFNC vs $25 \%$ for CPAP vs $28 \%$ for NIV, and an unadjusted mortality rate of $16 \%$ for HFNC vs $30 \%$ for CPAP vs $30 \%$ for NIV). ${ }^{23}$ However, HFNC was applied in subjects who were less ill (mean \pm SD $\mathrm{P}_{\mathrm{aO}_{2}} / \mathrm{F}_{\mathrm{IO}_{2}}, 166 \pm 65 \mathrm{~mm} \mathrm{Hg}$ ) compared with NIV (mean \pm $\mathrm{SD} \mathrm{P}_{\mathrm{aO}_{2}} / \mathrm{F}_{\mathrm{IO}_{2}}, 138 \pm 66 \mathrm{~mm} \mathrm{Hg}$ ) and $\mathrm{CPAP}$ (mean $\pm \mathrm{SD}$ $\mathrm{P}_{\mathrm{aO}_{2}} / \mathrm{F}_{\mathrm{IO}_{2}}, 151 \pm 90 \mathrm{~mm} \mathrm{Hg}$ ), which reflected the clinicians' attitudes to start the latter two in subjects in whom a relatively high level of external PEEP might be indicated. ${ }^{23}$ Another retrospective study performed in the ICU compared the outcome of subjects treated with HFNC with a casematched group treated with conventional oxygen therapy in subjects with COVID-19. ${ }^{64}$ The median $\mathrm{P}_{\mathrm{aO}_{2}} / \mathrm{F}_{\mathrm{IO}_{2}}$ did not differ between the 2 groups median (IQR) (126 [86-189] $\mathrm{mm} \mathrm{Hg}$ in the subjects on HFNC vs 130 [97-195] mm Hg in the subjects on standard oxygen therapy) ${ }^{64}$ However, the proportion of the subjects who required invasive mechanical ventilation on day 28 was significantly lower in the HFNC group (55\% vs $72 \% ; P<.001)$, although no difference was found in the mortality rate. ${ }^{64}$

In a retrospective analysis of subjects with COVID-19 and with moderate-to-severe acute hypoxemic respiratory failure, Patel et $\mathrm{al}^{65}$ found that application of HFNC may substantially reduce the need for invasive mechanical ventilation and escalation of NIV, with no apparent effect on mortality. In particular, $23.3 \%$ of the subjects were initially treated with HFNC, of whom $64.4 \%$ remained on HFNC, which showed a significant improvement in oxygenation and reduction in the incidence of hospital-acquired pneumonia compared with those who progressed to intubation or NIV.$^{65}$ A single-center RCT on 22 subjects with severe COVID-19 showed that early treatment with HFNC improved oxygenation and breathing frequency, even infectious indices, and reduced ICU length of stay compared with conventional oxygen therapy. ${ }^{66}$ In addition, the early use of HFNC is an effective respiratory strategy according to a recent retrospective multi-center study, ${ }^{67}$ which showed that patients with HFNC failure had a poor prognosis, with a hospital mortality rate of $65 \%$.

A recent propensity-matched cohort study assessed the role of HFNC in 122 subjects who were critically ill with COVID-19-associated acute hypoxemic respiratory failure and who had received either HFNC or early intubation on ICU admission. ${ }^{68}$ HFNC use was associated with increased ventilator-free days and reduced ICU length of stay, without a significant difference in all-cause in-hospital mortality. ${ }^{68}$

Moreover, data on patients with COVID-19 and with donot-intubate/do-not-resuscitate status are available. Franco et $\mathrm{al}^{23}$ reported nearly $7 \%$ of subjects (12/163) with do-notintubate orders treated with HFNC outside the ICU. However, in a large cohort study of 900 subjects with cancer and COVID-19, 132 subjects (14\%) were still admitted to the ICU and $116(12 \%)$ required invasive mechanical ventilation. ${ }^{71}$ We can conclude that HFNC may offer several advantages, reduce the intubation risk compared with conventional oxygen therapy, and represent a valid alternative to NIV in patients with severe COVID-19. However, RCTs are needed to effectively address the role of HFNC in this type of acute hypoxemic respiratory failure. Because pulmonary embolism, acute kidney injury, and myocardial injury are reported in a much higher proportion than nonCOVID-19 ARDS, ${ }^{72}$ the mortality rate may represent a more-complex outcome in this disease, not entirely affected by different noninvasive respiratory support strategies.

\section{Advantages of HFNC Combined With Prone Positioning}

By following the strong evidence on the application of prone positioning in patients with typical ARDS who are 
undergoing invasive mechanical ventilation, ${ }^{83}$ awake prone positioning in patients with COVID-19 has been increasingly reported in the COVID-19 literature, ${ }^{74,75,80}$ which demonstrate improvements in oxygenation when used with HFNC or NIV. ${ }^{73}$ However, to date, evidence for prone positioning in this population includes a few small single-center cohort studies. ${ }^{74-82}$ The rationale for using prone positioning in patients who are not intubated is based on the redistribution of the ventilation-to-perfusion ratio to spared lung regions, which are better ventilated. ${ }^{83}$ Therefore, improved oxygenation by lung recruitment of previously dependent areas reduces the shunt, ${ }^{84,85}$ which decreases hypoxemic vasoconstriction and improves pulmonary vascular resistance and right-ventricular function. ${ }^{86}$ In addition, during the prone position, chest wall compliance decreases, which explains, in part, a more homogeneous distribution of ventilation and regional lung stress. It also reduces the risk of ventilation-induced lung injury and, possibly, pendelluft. ${ }^{87}$

Based on the physiologic benefits and available data, some investigators ${ }^{83,84,85}$ hypothesized that patients with COVID19 and with respiratory distress at high risk for intubation might benefit from prone positioning. Ding et $\mathrm{al}^{88}$ reported the use of prone positioning in awake patients for the first time, which showed a reduction in the intubation rate in subjects with moderate-to-severe ARDS when treated with prone positioning combined with NIV or HFNC. In a retrospective study of 610 subjects from China, 10\% of subjects with COVID-19 were managed with early HFNC and awake prone positioning, which achieved a lower need for invasive mechanical ventilation ( $<1 \%$ vs a national average of $2.3 \%)$ and lower mortality ( $3.83 \%$ vs $4.34 \%$, respectively). ${ }^{73}$

$\mathrm{Xu}$ et $\mathrm{al}^{75}$ reported the effects of early awake prone positioning combined with HFNC in 10 subjects with COVID-19 who showed an improvement in $\mathrm{P}_{\mathrm{aO}_{2}} / \mathrm{F}_{\mathrm{IO}_{2}}$ after prone positioning and avoiding intubation in all the subjects. In contrast, Elharrar et $\mathrm{al}^{74}$ found that oxygenation improved during prone positioning only in 6 of 24 study participants (25\%). Furthermore, self-proning was not well tolerated in nearly $13 \%-25 \%$ of the subjects, with most reports using helmet CPAP or NIV. Therefore, we can speculate that HFNC may be more comfortable and feasible for the mobility of patients during self-proning. Recently, a large prospective multi-center observational cohort study that analyzed prone positioning in 55 of 199 awake subjects with COVID-19-associated acute hypoxemic respiratory failure who received HFNC showed that the use of awake prone positioning as an add-on therapy to HFNC did not reduce the risk of intubation or affect 28-d mortality, which showed a trend toward delayed intubation compared with HFNC alone. ${ }^{82}$ These data are similar to reports on prone positioning during helmet CPAP or conventional oxygen therapy in which the patients who responded to prone positioning treatment had no significant difference in intubation rate compared with non-responders. ${ }^{89}$
In conclusion, prone positioning may significantly improve gas exchange in patients with COVID-19 who were treated with noninvasive respiratory support devices. However, how this may affect the final outcome is not yet well established. Moreover, the use of prone positioning in patients with COVID-19 who are not intubated and treated with HNFC is yet to be addressed, and some RCTs are still ongoing (Table 2).

\section{Aerosol-Generating Risk}

Aerosol production by the patient's airways contains particles that range in size from 0.1 to $100 \mu \mathrm{m}$; the smaller the droplet is, the longer the air dispersion lasts. Droplets (particles $>5 \mu \mathrm{m}$ ) are produced by the upper airway ${ }^{90}$ and are at a higher risk of dispersion during conventional oxygen therapy and noninvasive respiratory support. Hence, supplemental low-flow conventional oxygen therapy has been considered a risk factor for the spread and airborne transmission of SARS-CoV-2. ${ }^{91}$ In addition, the fear that higher flows will increase virus aerosolization and environmental contamination ${ }^{92}$ has listed HFNC as an aerosol-generating procedure by health-care agencies, such as Public Health England ${ }^{93}$ and the National Institutes of Health, ${ }^{94}$ despite the lack of robust scientific evidence. ${ }^{95}$ Consequently, the HFNC utilization rate was relatively low during the early stages of the COVID-19 pandemic. $^{7}$

Dhand and $\mathrm{Li}^{96}$ recently pointed out the difference between aerosol-generating and aerosol-dispersing procedures. The investigators highlighted that coughing and procedures that provoke cough (ie, suctioning, intubation, bronchoscopy) generate a burst of bioaerosol, whereas HFNC, NIV, or conventional oxygen therapy are only dispersing the bioaerosol generated by patients to a greater distance. ${ }^{96}$ However, the aerosol generation and dispersion phenomenon has been studied predominantly through experimental studies ${ }^{7}$ that used marked smoke to simulate aerosols (particles $<1 \mu \mathrm{m}$ ) rather than measuring particle spread. Therefore, the actual risk of infection transmission has not been quantified. ${ }^{97}$

Hui et $\mathrm{al}^{98}$ investigated the direct visualization of exhaled smoke dispersion (with particle sizes of $\sim 1 \mu \mathrm{m}$ ) on a human patient simulator in a negative pressure room during a normal breathing pattern and mild respiratory distress. The investigators detected a higher smoke dispersion with HFNC at $60 \mathrm{~L} / \mathrm{min}$ compared with $10 \mathrm{~L} / \mathrm{min} .{ }^{98}$ However, they did not find considerable differences in the level of smoke between $\mathrm{HFNC}$ at $60 \mathrm{~L} / \mathrm{min}, \mathrm{CPAP}$ via nasal pillow at $20 \mathrm{~cm} \mathrm{H}_{2} \mathrm{O}$, or via oronasal mask at $20 \mathrm{~cm} \mathrm{H}_{2} \mathrm{O} .{ }^{98}$ Indeed, they found a significant increase in exhaled smoke dispersion (up to $620 \mathrm{~mm}$ ) laterally when the connection between HFNC nasal prongs and the simulated nares were loose. ${ }^{98}$ 


\section{HFNC AND COVID-19}

More recently, studies have investigated the dispersion of contaminated aerosols during quiet and forced breathing or coughing, with or without HFNC, and reported different findings. Roberts et $\mathrm{al}^{99}$ studied healthy adults breathing spontaneously, with or without HFNC, at flows of 30 and $60 \mathrm{~L} / \mathrm{min}$ at rest and after violent exhalation (snorting) and showed no increase in aerosol dispersion of intermediate size particles of $25-250 \mu \mathrm{m}$ with HFNC at rest compared with snorting. Loh et $\mathrm{al}^{100}$ studied healthy adults breathing spontaneously with or without HFNC at $60 \mathrm{~L} / \mathrm{min}$ and found that it did not impact the distance of droplet spread, regardless of HFNC use.

Jermy et $\mathrm{al}^{101}$ assessed airborne particle dispersion in human volunteers breathing at rest, coughing, snorting, or sneezing, with or without HFNC. They found a significant protective effect from sneezing during HFNC, which suggested that the high flow generated by HFNC may prevent the exit of infected air. ${ }^{101}$ They also showed that it would take $86 \mathrm{~h}$ of quiet breathing with $\mathrm{HFNC}$ at $60 \mathrm{~L} / \mathrm{min}$ to release the same quantity of nasal fluid as a minute of coughing with no therapy. ${ }^{101}$ Kotoda et al ${ }^{102}$ assessed potential pathogen dispersion with or without HFNC at $60 \mathrm{~L} / \mathrm{min}$ in a static nonbreathing model by using thickened water or fresh yeast solution to mimic saliva and nasal mucus secretion and showed no increase in the risk of droplet dispersion with HFNC.

The only evidence in vivo on actual patients in the ICU is a recent RCT that showed that HFNC at $60 \mathrm{~L} / \mathrm{min}$ did not generate a significantly different level of airborne bacterial contamination in the air sampled than did oxygen therapy delivered via a face mask. ${ }^{103}$ Nevertheless, because the study analyzed bacteria rather than viruses, the evidence did not clarify this divisive issue. More recent studies compared all devices applicable to the patient's face (conventional oxygen therapy, HFNC, NIV). Li et $\mathrm{al}^{104}$ summarized all published studies by using an experimental model that looks at the exhaled smoke dispersion distances with different devices: HFNC at different flows (10, 30, 60 $\mathrm{L} / \mathrm{min})$, simple mask $(10,15 \mathrm{~L} / \mathrm{min})$, non-rebreather mask $(10 \mathrm{~L} / \mathrm{min})$, and air-entrainment mask $\left(6 \mathrm{~L} / \mathrm{min}\right.$ with $\mathrm{F}_{\mathrm{IO}_{2}}$ of 0.4 or 0.5$)$. The smoke dispersion distance with the higher flow of HFNC $(17.2 \pm 3.3 \mathrm{~cm})$ was lower than that of the non-rebreather $(24.6 \pm 2.2 \mathrm{~cm})$ or the air-entrainment mask $(39.7 \pm 1.6 \mathrm{~cm})$, which indicated that HFNC had the lowest risk of bioaerosol dispersion. ${ }^{104}$

Gaeckle et $\mathrm{al}^{105}$ studied healthy adults and compared non-humidified nasal cannula at $4 \mathrm{~L} / \mathrm{min}$; facemask at 15 $\mathrm{L} / \mathrm{min}$; HFNC at 10,30 , and $50 \mathrm{~L} / \mathrm{min}$; and NIV with an inspiratory positive airway pressure/expiratory positive airway pressure of $12 / 5$ and $20 / 10 \mathrm{~cm} \mathrm{H}_{2} \mathrm{O}$. They measured particles of sizes 0.37 and $20 \mu \mathrm{m}$ during normal breathing, talking, deep breathing, and coughing, and found an increased number of particles during coughing; however, the investigators found no significant differences between HFNC and/or NIV and conventional oxygen therapy in different testing conditions. ${ }^{105} \mathrm{~A}$ proposed way to mitigate the aerosol spread when using HFNC is to apply a surgical mask on top of the patient's face, as promoted in the early course of the pandemic in China. ${ }^{106}$ Moreover, it has recently been shown that this measure further reduces the velocity of exhaled gas flow, droplet deposition, ${ }^{107-109}$ and concentration of $0.5-5 \mu \mathrm{m}$-sized particles, particularly $30.5 \mathrm{~cm}$ from the patient's face. ${ }^{110}$

Overall, the available evidence shows that HFNC is no worse than conventional oxygen delivery devices or NIV in terms of dispersion of a patient-generated bioaerosol. A recent observational study of 28 subjects treated with HFNC showed none of the ICU staff were infected during the study period and the following $14 \mathrm{~d} \cdot{ }^{63} \mathrm{HFNC}$, with its interface characterized by soft nasal prongs with large bores that fill up approximately half of the area of patients' nostrils, minimizes the aerosol-generation risk. Placing a surgical mask over the patient's face during HFNC treatment may further decrease the bioaerosol dispersion distance. Real-world assessment of droplets and aerosols spread in genuine clinical environments is urgently needed, along with testing measures to mitigate these risks.

\section{HFNC Use in COVID-19}

The role of noninvasive respiratory support and HFNC in suspected or confirmed SARS-CoV-2 infection has not yet been definitively clarified. Furthermore, no large RCTs exist on the use of HFNC or CPAP and/or NIV in patients with acute hypoxemic respiratory failure caused by a pandemic viral illness. ${ }^{7}$ In the early stages of the current pandemic, initial concerns about the risk of bioaerosol dispersion and delayed intubation led some scientific societies to limit or not recommend the application of HFNC and other noninvasive respiratory support devices with different and sometimes opposite recommendations between national and international organizations. ${ }^{111}$ Societies' recommendations on the use of HFNC in COVID-19-associated acute hypoxemic respiratory failure are shown in Table S1 (see the supplementary materials at http://www. rcjournal.com).

\section{Clinical Implications, Critical Issues, and Limitations}

HFNC usage during the current pandemic varied across studies and countries (Table 2)., ${ }^{712,113}$ The mean rate of HFNC usage reported was $22.8 \%$ in China and ranged from $4.8 \%$ to $42 \%$ in the United States, ${ }^{5,56,112-114}$ whereas data from other countries are not available. The criteria to start HFNC were also heterogeneous among the published studies with different initial $\mathrm{P}_{\mathrm{aO}_{2}} / \mathrm{F}_{\mathrm{IO}_{2}}$ values (Table 2, Fig. 1) and outcomes (Table 2, Fig. 2). The actual suggestions on HFNC use are mainly based on expert opinion and 


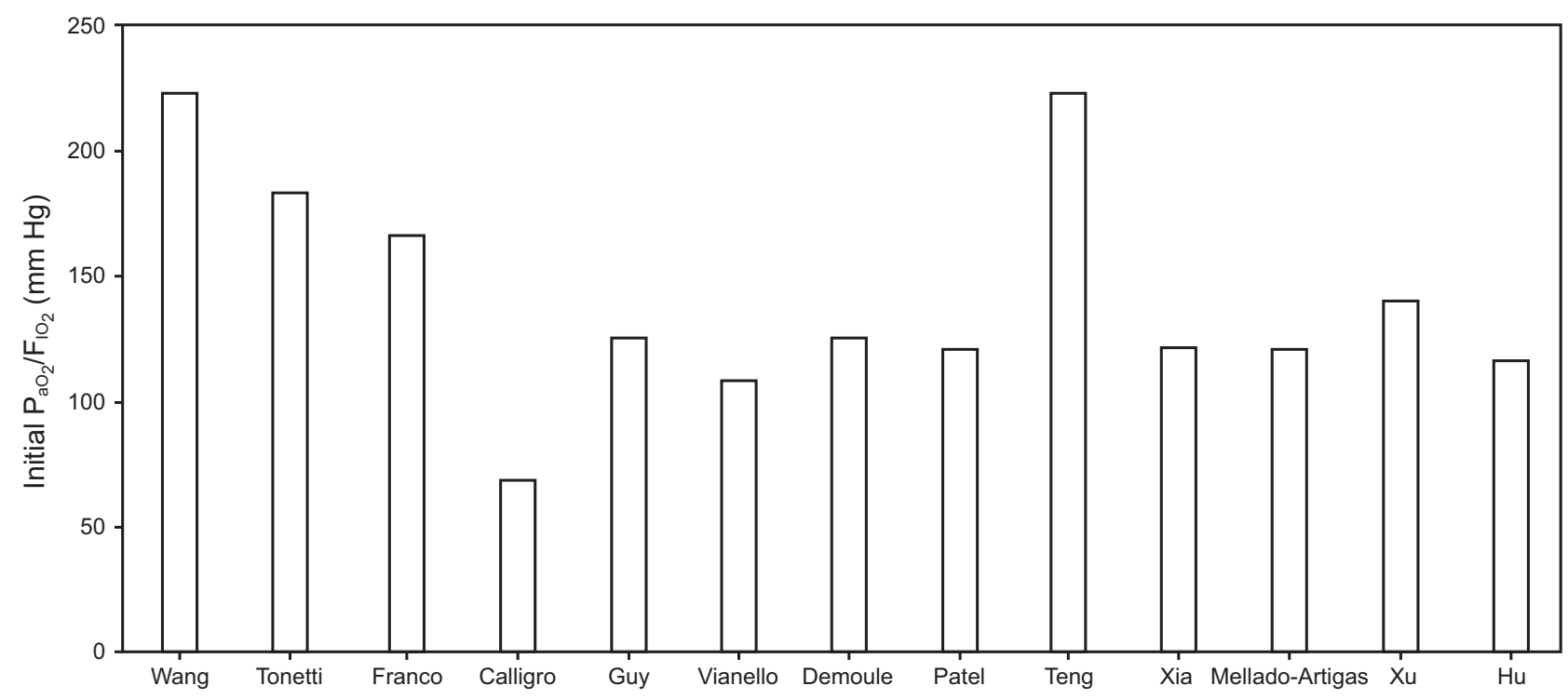

Fig. 1. Initial $\mathrm{P}_{\mathrm{aO}_{2}} / \mathrm{F}_{\mathrm{IO}_{2}}$ before starting high-flow nasal cannula in published studies on coronavirus disease 2019 (COVID-19). Studies not listed did not report data on initial $\mathrm{P}_{\mathrm{aO}_{2}} / \mathrm{F}_{\mathrm{IO}_{2}}$.

emerging retrospective data in patients with COVID-19 from countries where outbreaks have occurred. ${ }^{111}$

Some physiologic studies showed a heterogeneous pattern of respiratory mechanics patterns that ranged from almost normal compliance to very stiff lungs, similar to classic ARDS. ${ }^{115}$ This may explain the variable severity of hypoxia associated with hypocapnia, with or, more frequently, without dyspnea and increased breathing frequency. ${ }^{116}$ In fact, hypocapnia is almost always a consequence of increased alveolar ventilation and, consequently, incremented transpulmonary pressure, which all patients experience to a different extent. ${ }^{117}$ Therefore, the breathing frequency and clinical evidence of respiratory distress are not sensitive in identifying patients with increased transpulmonary pressure, predictive of selfinflicted lung injury. ${ }^{118}$ Meanwhile, these data give HFNC a critical role because it effectively reduces the transpulmonary pressure by the same amount as NIV, ${ }^{38,42}$ without the harmful effects of delivering a large tidal volume ${ }^{35}$ as frequently seen during NIV due to the joint action of the patient's respiratory drive to breathe and the pressure support provided.

However, all the above-mentioned physiologic considerations raised some crucial points in applying HFNC to COVID-19 pneumonia. First, HFNC cannot generate or ensure an increased and stable continuous alveolar pressure; this is an important issue because lung recruitment is more likely to be achieved in COVID-19 pneumonia than in "usual" ARDS. ${ }^{115}$ Moreover, it is unclear whether the favorable effects of HFNC may be extended to patients with a predominantly vascular mechanism of respiratory failure due to pulmonary thromboembolism, even if we can assume that the ability to keep $\mathrm{F}_{\mathrm{IO}_{2}}$ stable and guarantee better oxygenation than conventional oxygen therapy could allow time for pharmacologic treatment to take effect. Moreover, compared with NIV or CPAP, HFNC can be more easily applied for patients during prone positioning, and the application of the combined treatments in the early phase of COVID-19 pneumonia may reduce the intubation rate. ${ }^{88}$

Another major concern is how and what we need to monitor to test the efficacy of HFNC and to avoid delaying intubation. ${ }^{103,119}$ In many patients, respiratory failure may be associated with a normal breathing frequency or a blunted perception of dyspnea, likely related to a dysfunction of cortical structures linked to viral neuroinvasiveness ${ }^{120}$; this may affect the sensitivity of parameters commonly proposed to monitor the efficacy of HFNC and to predict its success or the timing of intubation. ${ }^{121}$ For example, the ROX index, defined as $\mathrm{S}_{\mathrm{pO}_{2}} / \mathrm{F}_{\mathrm{IO}_{2}} /$ breathing frequency, was shown to predict a high risk of intubation in non-COVID-19 acute hypoxemic respiratory failures treated with HFNC if $<4.88$ at $12 \mathrm{~h}^{122}$

$\mathrm{Hu}$ et $\mathrm{al}^{70}$ showed that the ROX index at 6,12 , and $24 \mathrm{~h}$ of HFNC initiation was closely related to patient prognosis, and Xia et $\mathrm{al}^{67}$ confirmed the ROX index as a good predictive capacity of HFNC outcomes. Furthermore, in a retrospective study by Chandel et al, ${ }^{123}$ the ROX index was sensitive in identifying subjects with COVID-19 successfully weaned from HFNC. Nevertheless, slightly different cutoff values than that reported for subjects without COVID-19 were observed. ${ }^{121}$ Ricard et $\mathrm{al}^{2}$ suggested an algorithm that uses the ROX index to avoid delayed intubation in patients with COVID-19. Patients with a ROX index of $<2.85,3.47$, and 3.85 after 2,6 , and $12 \mathrm{~h}$ of HFNC 
HFNC AND COVID-19

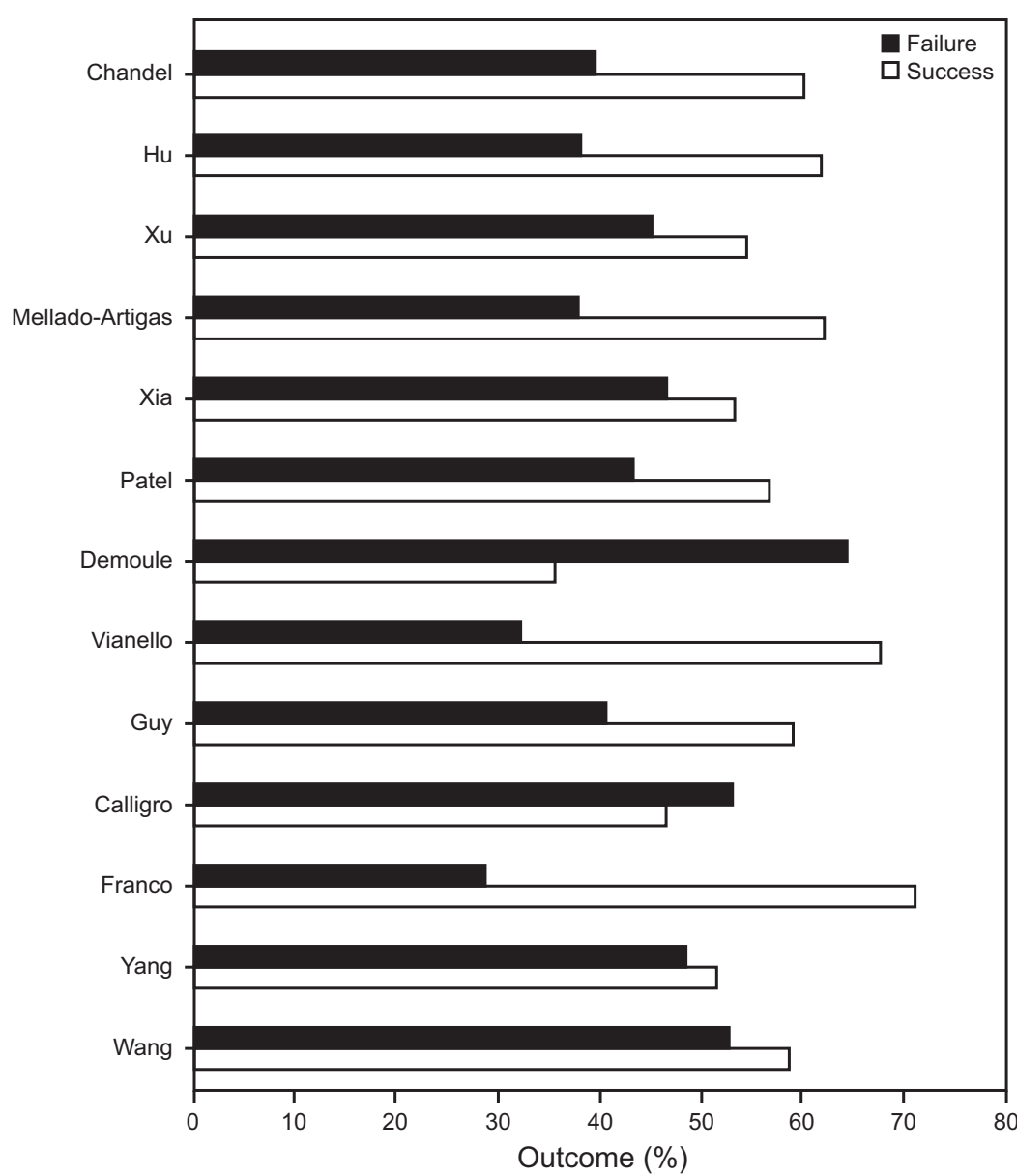

Fig. 2. Main outcomes of high flow nasal cannula in published studies on coronavirus disease 2019 (COVID-19).

therapy, respectively, were more likely to fail, which highlights the importance of a dynamic assessment of the ROX index. Measurement of the alveolar-to-arterial oxygen gradient may be more precise in interpreting arterial oxygenation and more helpful in monitoring the effect of HFNC because it considers alveolar ventilation. ${ }^{124}$ The same $\mathrm{P}_{\mathrm{aO}}$ value may be an expression of different levels of alveolar ventilation (and transpulmonary pressure as a surrogate) when associated with varying values of $\mathrm{P}_{\mathrm{aCO}}$; therefore, similar $\mathrm{P}_{\mathrm{aO}_{2}} / \mathrm{F}_{\mathrm{IO}_{2}}$ might be associated with a different alveolar-to-arterial oxygen gradient value. ${ }^{125}$

\section{Summary}

HFNC may play a role in managing patients with COVID-19 pneumonia with a low risk of bioaerosol dispersion into the environment. Early application, together with prone positioning, may significantly improve gas exchange and the outcome in these patients. However, the persistence of high breathing frequency and/or respiratory distress $1 \mathrm{~h}$ after application is associated with an increased risk of failure.
Therefore, meticulous monitoring of patients on HFNC is crucial to avoid prolonged treatment and delay intubation.

\section{REFERENCES}

1. Rochwerg B, Einav S, Chaudhuri D, Mancebo J, Mauri T, Helviz Y, et al. The role for high flow nasal cannula as a respiratory support strategy in adults: a clinical practice guideline. Intensive Care Med 2020;46(12):2226-2237.

2. Ricard J-D, Roca O, Lemiale V, Corley A, Braunlich J, Jones P, et al. Use of nasal high flow oxygen during acute respiratory failure. Intensive Care Med 2020;46(12):2238-2247.

3. Wang K, Zhao W, Li J, Shu W, Duan J. The experience of high-flow nasal cannula in hospitalized patients with 2019 novel coronavirusinfected pneumonia in two hospitals of Chongqing. Ann Intensive Care 2020;10(1):37.

4. Tonetti T, Grasselli G, Zanella A, Pizzilli G, Fumagalli R, Piva S, et al. Use of critical care resources during the first 2 weeks (February 24March 8, 2020) of the Covid-19 outbreak in Italy. Ann Intensive Care 2020;10(1):133.

5. Yang X, Yu Y, Xu J, Shu H, Xia J, Liu H, et al. Clinical course and outcomes of critically ill patients with SARS-CoV-2 pneumonia in Wuhan, China: a single-centered, retrospective, observational study. Lancet Respir Med 2020;8(5):475-481.

6. Agarwal A, Basmaji J, Muttalib F, Granton D, Chaudhuri D, Chetan D, et al. High-flow nasal cannula for acute hypoxemic 
respiratory failure in patients with COVID-19: systematic reviews of effectiveness and its risks of aerosolization, dispersion, and infection transmission. Can J Anaesth 2020;67 (9):1217-1248.

7. Crimi C, Noto A, Cortegiani A, Impellizzeri P, Elliott $\mathrm{M}$, Ambrosino N, Gregoretti C. Noninvasive respiratory support in acute hypoxemic respiratory failure associated with COVID-19 and other viral infections. Minerva Anestesiol 2020;86 (11):1190-1204

8. Parke RL, Eccleston ML, McGuinness SP. The effects of flow on airway pressure during nasal high-flow oxygen therapy. Respir Care 2011;56(8):1151-1155

9. Parke RL, McGuinness SP. Pressures delivered by nasal high flow oxygen during all phases of the respiratory cycle. Respir Care 2013;58(10):1621-1624.

10. Groves N, Tobin A. High flow nasal oxygen generates positive airway pressure in adult volunteers. Aust Crit Care 2007;20(4):126-131.

11. Ritchie JE, Williams AB, Gerard C, Hockey H. Evaluation of a humidified nasal high-flow oxygen system, using oxygraphy, capnography and measurement of upper airway pressures. Anaesth Intensive Care 2011;39(6):1103-1110.

12. Kilgour E, Rankin N, Ryan S, Pack R. Mucociliary function deteriorates in the clinical range of inspired air temperature and humidity. Intensive Care Med 2004;30(7):1491-1494.

13. Helviz Y, Einav S. A systematic review of the high-flow nasal cannula for adult patients. Crit Care 2018;22(1):71.

14. Chidekel A, Zhu Y, Wang J, Mosko JJ, Rodriguez E, Shaffer TH. The effects of gas humidification with high-flow nasal cannula on cultured human airway epithelial cells. Pulm Med 2012;2012:380686.

15. Delorme M, Bouchard P-A, Simon M, Simard S, Lellouche F. Effects of high-flow nasal cannula on the work of breathing in patients recovering from acute respiratory failure. Crit Care Med 2017;45(12):1981-1988.

16. Mauri T, Alban L, Turrini C, Cambiaghi B, Carlesso E, Taccone P, et al. Optimum support by high-flow nasal cannula in acute hypoxemic respiratory failure: effects of increasing flow rates. Intensive Care Med 2017;43(10):1453-1463.

17. Motoyasu A, Moriyama K, Okano H, Yorozu T. High-flow nasal cannula therapy reduced the respiratory rate and respiratory distress in a standard model simulator and in patients with hypoxemic respiratory failure. Chron Respir Dis 2019;16:147997311988089.

18. Corley A, Caruana LR, Barnett AG, Tronstad O, Fraser JF. Oxygen delivery through high-flow nasal cannulae increase end-expiratory lung volume and reduce respiratory rate in post-cardiac surgical patients. Br J Anaesth 2011;107(6):998-1004.

19. Mündel T, Feng S, Tatkov S, Schneider H. Mechanisms of nasal high flow on ventilation during wakefulness and sleep. J Appl Physiol (1985) 2013;114(8):1058-1065.

20. Möller W, Feng S, Domanski U, Franke K-J, Celik G, Bartenstein P, et al. Nasal high flow reduces dead space. J Appl Physiol (1985) 2017;122(1):191-197.

21. Frat J-P, Thille AW, Mercat A, Girault C, Ragot S, Perbet S, et al. High-flow oxygen through nasal cannula in acute hypoxemic respiratory failure. N Engl J Med 2015;372(23):2185-2196.

22. Frat J-P, Coudroy R, Marjanovic N, Thille AW. High-flow nasal oxygen therapy and noninvasive ventilation in the management of acute hypoxemic respiratory failure. Ann Transl Med 2017;5(14):297.

23. Franco C, Facciolongo N, Tonelli R, Dongilli R, Vianello A, Pisani $\mathrm{L}$, et al. Feasibility and clinical impact of out-of-ICU noninvasive respiratory support in patients with COVID-19-related pneumonia. Eur Respir J 2020;56(5):2002130.

24. Villarreal-Fernandez E, Patel R, Golamari R, Khalid M, DeWaters A, Haouzi P. A plea for avoiding systematic intubation in severely hypoxemic patients with COVID-19-associated respiratory failure. Crit Care 2020;24(1):337.

25. Nasa P, Azoulay E, Khanna AK, Jain R, Gupta S, Javeri Y, et al. Expert consensus statements for the management of COVID-19related acute respiratory failure using a Delphi method. Crit Care 2021;25(1): 106 .

26. Brochard L, Slutsky A, Pesenti A. Mechanical ventilation to minimize progression of lung injury in acute respiratory failure. Am J Respir Crit Care Med 2017;195(4):438-442.

27. Gattinoni L, Chiumello D, Rossi S. COVID-19 pneumonia: ARDS or not? Crit Care 2020;24(1):154.

28. Torrego A, Pajares V, Fernández-Arias C, Vera P, Mancebo J. Bronchoscopy in patients with COVID-19 with invasive mechanical ventilation: a single-center experience. Am J Respir Crit Care Med 2020;202(2):284-287.

29. Liu Q, Wang RS, Qu GQ, Wang YY, Liu P, Zhu YZ, et al. Gross examination report of a COVID-19 death autopsy. Fa Yi Xue Za Zhi 2020;36(1):21-23.

30. Xu Z, Shi L, Wang Y, Zhang J, Huang L, Zhang C, et al. Pathological findings of COVID-19 associated with acute respiratory distress syndrome. Lancet Respir Med 2020;8(4):420-422.

31. Tian S, Xiong Y, Liu H, Niu L, Guo J, Liao M, Xiao S-Y. Pathological study of the 2019 novel coronavirus disease (COVID19) through postmortem core biopsies. Mod Pathol 2020;33(6):10071014.

32. Mauri T, Galazzi A, Binda F, Masciopinto L, Corcione N, Carlesso $\mathrm{E}$, et al. Impact of flow and temperature on patient comfort during respiratory support by high-flow nasal cannula. Crit Care 2018;22 (1): 120 .

33. Rochwerg B, Brochard L, Elliott MW, Hess D, Hill NS, Nava S, et al. Official ERS/ATS clinical practice guidelines: noninvasive ventilation for acute respiratory failure. Eur Respir J 2017;50 (2): 1602426 .

34. Carteaux G, Millan-Guilarte T, De Prost N, Razazi K, Abid S, Thille AW, et al. Failure of noninvasive ventilation for de novo acute hypoxemic respiratory failure: role of tidal volume. Crit Care Med 2016;44(2):282-290.

35. Frat J-P, Ragot S, Coudroy R, Constantin J-M, Girault C, Prat G, et al. Predictors of intubation in patients with acute hypoxemic respiratory failure treated with a noninvasive oxygenation strategy. Crit Care Med 2018;46(2):208-215.

36. Tonelli R, Fantini R, Tabbi L, Castaniere I, Pisani L, Pellegrino MR, et al. Inspiratory effort assessment by esophageal manometry early predicts noninvasive ventilation outcome in de novo respiratory failure. A pilot study. Am J Respir Crit Care Med 2020;202(4):558-567.

37. Patel BK, Wolfe KS, Pohlman AS, Hall JB, Kress JP. Effect of noninvasive ventilation delivered by helmet vs face mask on the rate of endotracheal intubation in patients with acute respiratory distress syndrome: a randomized clinical trial. JAMA 2016;315(22):24352441.

38. Grieco DL, Menga LS, Raggi V, Bongiovanni F, Anzellotti GM, Tanzarella ES, et al. Physiological comparison of high-flow nasal cannula and helmet noninvasive ventilation in acute hypoxemic respiratory failure. Am J Respir Crit Care Med 2020;201(3):303-312.

39. Liu J, Duan J, Bai L, Zhou L. Noninvasive ventilation intolerance: characteristics, predictors, and outcomes. Respir Care 2016;61 (3):277-284

40. Cortegiani A, Crimi C, Noto A, Helviz Y, Giarratano A, Gregoretti C, Einav S. Effect of high-flow nasal therapy on dyspnea, comfort, and respiratory rate. Crit Care 2019;23(1):201.

41. Racca F, Appendini L, Berta G, Barberis L, Vittone F, Gregoretti C, et al. Helmet ventilation for acute respiratory failure and nasal skin breakdown in neuromuscular disorders. Anesth Analg 2009;109 (1):164-167. 
42. Mauri T, Turrini C, Eronia N, Grasselli G, Volta CA, Bellani G, Pesenti A. Physiologic effects of high-flow nasal cannula in acute hypoxemic respiratory failure. Am J Respir Crit Care Med 2017;195 (9):1207-1215.

43. Villar-Alvarez F, Moreno-Zabaleta R, Mira-Solves JJ, CalvoCorbella E, Diaz-Lobato S, González-Torralba F, et al. Do not do in COPD: consensus statement on overuse. Int $\mathrm{J}$ Chron Obstruct Pulmon Dis 2018;13:451-463.

44. Nishimura M. High-flow nasal cannula oxygen therapy in adults: physiological benefits, indication, clinical benefits, and adverse effects. Respir Care 2016;61(4):529-541.

45. Demoule A, Chevret S, Carlucci A, Kouatchet A, Jaber S, Meziani F, et al. Changing use of noninvasive ventilation in critically ill patients: trends over 15 years in francophone countries. Intensive Care Med 2016;42(1):82-92.

46. Singer P, Rattanachaiwong $\mathrm{S}$. To eat or to breathe? The answer is both! Nutritional management during noninvasive ventilation. Crit Care 2018;22(1):27.

47. Peters SG, Holets SR, Gay PC. High-flow nasal cannula therapy in do-not-intubate patients with hypoxemic respiratory distress. Respir Care 2013;58(4):597-600.

48. Wilson ME, Mittal A, Dobler CC, Curtis JR, Majzoub AM, Soleimani J, et al. High-flow nasal cannula oxygen in patients with acute respiratory failure and do-not-intubate or do-not-resuscitate orders: a systematic review. J Hosp Med 2020;15(2):101-106.

49. Cortegiani A, Crimi C, Sanfilippo F, Noto A, Di Falco D, Grasselli $\mathrm{G}$, et al. High flow nasal therapy in immunocompromised patients with acute respiratory failure: a systematic review and meta-analysis. J Crit Care 2019;50:250-256.

50. Hernández G, Vaquero C, Colinas L, Cuena R, González P, Canabal A, et al. Effect of postextubation high-flow nasal cannula vs noninvasive ventilation on reintubation and postextubation respiratory failure in high-risk patients: a randomized clinical trial. JAMA 2016;316 (15): $1565-1574$.

51. Hernández G, Vaquero C, Gonzalez P, Subira C, Frutos-Vivar F, Rialp G, et al. Effect of postextubation high-flow nasal cannula vs conventional oxygen therapy on reintubation in low-risk patients: a randomized clinical trial. JAMA 2016;315(13):1354-1361

52. Maggiore SM, Idone FA, Vaschetto R, Festa R, Cataldo A, Antonicelli $\mathrm{F}$, et al. Nasal high-flow versus Venturi mask oxygen therapy after extubation. Effects on oxygenation, comfort, and clinical outcome. Am J Respir Crit Care Med 2014;190(3):282-288.

53. Sztrymf B, Messika J, Bertrand F, Hurel D, Leon R, Dreyfuss D, Ricard J-D. Beneficial effects of humidified high flow nasal oxygen in critical care patients: a prospective pilot study. Intensive Care Med 2011;37(11):1780-1786.

54. Bell N, Hutchinson CL, Green TC, Rogan E, Bein KJ, Dinh MM. Randomised control trial of humidified high flow nasal cannulae versus standard oxygen in the emergency department. Emerg Med Australas 2015;27(6):537-541.

55. Stéphan F, Barrucand B, Petit P, Rézaiguia-Delclaux S, Médard A, Delannoy B, et al. High-flow nasal oxygen vs noninvasive positive airway pressure in hypoxemic patients after cardiothoracic surgery: a randomized clinical trial. JAMA 2015;313(23):2331-2339.

56. Zhao H, Wang H, Sun F, Lyu S, An Y. High-flow nasal cannula oxygen therapy is superior to conventional oxygen therapy but not to noninvasive mechanical ventilation on intubation rate: a systematic review and meta-analysis. Crit Care 2017;21(1):184

57. Ou X, Hua Y, Liu J, Gong C, Zhao W. Effect of high-flow nasal cannula oxygen therapy in adults with acute hypoxemic respiratory failure: a meta-analysis of randomized controlled trials. CMAJ 2017;189 (7):E260-E267.

58. Ni Y-N, Luo J, Yu H, Liu D, Ni Z, Cheng J, et al. Can high-flow nasal cannula reduce the rate of endotracheal intubation in adult patients with acute respiratory failure compared with conventional oxygen therapy and noninvasive positive pressure ventilation?: a systematic review and meta-analysis. Chest 2017;151(4):764-775.

59. Rochwerg B, Granton D, Wang DX, Helviz Y, Einav S, Frat JP, et al. High flow nasal cannula compared with conventional oxygen therapy for acute hypoxemic respiratory failure: a systematic review and meta-analysis. Intensive Care Med 2019;45(5):563-572.

60. Pinkham M, Tatkov S. Effect of flow and cannula size on generated pressure during nasal high flow. Crit Care 2020;24(1):248.

61. Calligaro GL, Lalla U, Audley G, Gina P, Miller MG, Mendelson M, et al. The utility of high-flow nasal oxygen for severe COVID-19 pneumonia in a resource-constrained setting: a multi-centre prospective observational study. EClinicalMedicine 2020;28:100570.

62. Guy T, Créac'hcadec A, Ricordel C, Salé A, Arnouat B, Bizec J-L, et al. High-flow nasal oxygen: a safe, efficient treatment for COVID19 patients not in an ICU. Eur Respir J 2020;56(5):2001154.

63. Vianello A, Arcaro G, Molena B, Turato C, Sukthi A, Guarnieri G, et al. High-flow nasal cannula oxygen therapy to treat patients with hypoxemic acute respiratory failure consequent to SARS-CoV-2 infection. Thorax 2020;75(11):998-1000.

64. Demoule A, Vieillard Baron A, Darmon M, Beurton A, Geri G, Voiriot G, et al. High-flow nasal cannula in critically ill patients with severe COVID-19. Am J Respir Crit Care Med 2020;202(7):10391042.

65. Patel M, Gangemi A, Marron R, Chowdhury J, Yousef I, Zheng M, et al. Retrospective analysis of high flow nasal therapy in COVID19-related moderate-to-severe hypoxaemic respiratory failure. BMJ Open Respir Res 2020;7(1):e000650.

66. Teng X-B, Shen Y, Han M-F, Yang G, Zha L, Shi J-F. The value of high-flow nasal cannula oxygen therapy in treating novel coronavirus pneumonia. Eur J Clin Invest 2021;51(3):e13435.

67. Xia J, Zhang Y, Ni L, Chen L, Zhou C, Gao C, et al. High-flow nasal oxygen in coronavirus disease 2019 patients with acute hypoxemic respiratory failure: a multicenter, retrospective cohort study. Crit Care Med 2020;48(11):e1079-e1086.

68. Mellado-Artigas R, Ferreyro BL, Angriman F, Hernández-Sanz M, Arruti E, Torres A, et al. COVID-19 Spanish ICU Network. Highflow nasal oxygen in patients with COVID-19-associated acute respiratory failure. Crit Care 2021;25(1):58.

69. Xu J, Yang X, Huang C, Zou X, Zhou T, Pan S, et al. A novel riskstratification models of the high-flow nasal cannula therapy in COVID-19 patients with hypoxemic respiratory failure. Front Med (Lausanne) 2020;7:607821.

70. Hu M, Zhou Q, Zheng R, Li X, Ling J, Chen Y, et al. Application of high-flow nasal cannula in hypoxemic patients with COVID-19: a retrospective cohort study. BMC Pulm Med 2020;20(1):324.

71. Kuderer NM, Choueiri TK, Shah DP, Shyr Y, Rubinstein SM, Rivera DR, et al. Clinical impact of COVID-19 on patients with cancer (CCC19): a cohort study. Lancet 2020;395(10241):1907-1918.

72. Puelles VG, Lütgehetmann M, Lindenmeyer MT, Sperhake JP, Wong MN, Allweiss L, et al. Multiorgan and renal tropism of SARSCoV-2. N Engl J Med 2020;383(6):590-592.

73. Sun Q, Qiu H, Huang M, Yang Y. Lower mortality of COVID-19 by early recognition and intervention: experience from Jiangsu Province. Ann Intensive Care 2020;10(1):33.

74. Elharrar X, Trigui Y, Dols A-M, Touchon F, Martinez S, Prud'homme E, Papazian L. Use of prone positioning in nonintubated patients with COVID-19 and hypoxemic acute respiratory failure. JAMA 2020;323(22):2336-2338.

75. Xu Q, Wang T, Qin X, Jie Y, Zha L, Lu W. Early awake prone position combined with high-flow nasal oxygen therapy in severe COVID-19: a case series. Crit Care 2020;24(1):250.

76. Caputo ND, Strayer RJ, Levitan R. Early self-proning in awake, nonintubated patients in the emergency department: a single ED's 


\section{HFNC AND COVID-19}

experience during the COVID-19 pandemic. Acad Emerg Med 2020;27(5):375-378

77. Sartini C, Tresoldi M, Scarpellini P, Tettamanti A, Carco F, Landoni G, Zangrillo A. Respiratory parameters in patients with COVID-19 after using noninvasive ventilation in the prone position outside the intensive care unit. JAMA 2020;323(22):2338-2340.

78. Damarla M, Zaeh S, Niedermeyer S, Merck S, Niranjan-Azadi A, Broderick B, Punjabi N. Prone positioning of non-intubated patients with COVID-19. Am J Respir Crit Care Med 2020;202(4):604-606.

79. Thompson AE, Ranard BL, Wei Y, Jelic S. Prone positioning in awake, nonintubated patients with COVID-19 hypoxemic respiratory failure. JAMA Intern Med 2020;180(11):1537-1539.

80. $\mathrm{Ng} \mathrm{Z}$, Tay WC, Ho CHB. Awake prone positioning for non-intubated oxygen dependent COVID-19 pneumonia patients. Eur Respir J 2020;56(1):2001198

81. Solverson K, Weatherald J, Parhar KKS. Tolerability and safety of awake prone positioning COVID-19 patients with severe hypoxemic respiratory failure. Can J Anaesth 2021;68(1):64-70.

82. Ferrando C, Mellado-Artigas R, Gea A, Arruti E, Aldecoa C, Adalia $\mathrm{R}$, et al. Awake prone positioning does not reduce the risk of intubation in COVID-19 treated with high-flow nasal oxygen therapy: a multicenter, adjusted cohort study. Crit Care 2020;24(1):597.

83. Scholten EL, Beitler JR, Prisk GK, Malhotra A. Treatment of ARDS with prone positioning. Chest 2017;151(1):215-224.

84. Bellani G, Messa C, Guerra L, Spagnolli E, Foti G, Patroniti N, et al. Lungs of patients with acute respiratory distress syndrome show diffuse inflammation in normally aerated regions: a [18F]-fluoro-2deoxy-D-glucose PET/CT study. Crit Care Med 2009;37(7):22162222.

85. Nyrén S, Mure M, Jacobsson H, Larsson SA, Lindahl SG. Pulmonary perfusion is more uniform in the prone than in the supine position: scintigraphy in healthy humans. J Appl Physiol (1985) 1999;86 (4):1135-1141.

86. Jozwiak M, Teboul J-L, Anguel N, Persichini R, Silva S, Chemla D, et al. Beneficial hemodynamic effects of prone positioning in patients with acute respiratory distress syndrome. Am J Respir Crit Care Med 2013;188(12):1428-1433.

87. Telias I, Katira BH, Brochard L. Is the prone position helpful during spontaneous breathing in patients with COVID-19? JAMA 2020;323 (22):2265-2267.

88. Ding L, Wang L, Ma W, He H. Efficacy and safety of early prone positioning combined with HFNC or NIV in moderate to severe ARDS: a multi-center prospective cohort study. Crit Care 2020;24 (1):28.

89. Coppo A, Bellani G, Winterton D, Di Pierro M, Soria A, Faverio P, et al. Feasibility and physiological effects of prone positioning in non-intubated patients with acute respiratory failure due to COVID19 (PRON-COVID): a prospective cohort study. Lancet Respir Med 2020;8(8):765-774

90. Wilson NM, Norton A, Young FP, Collins DW. Airborne transmission of severe acute respiratory syndrome coronavirus-2 to healthcare workers: a narrative review. Anaesthesia 2020;75(8):1086-1095.

91. Goldhaber-Fiebert SN, Greene JA, Garibaldi BT. Low-flow nasal cannula oxygen and potential nosocomial spread of COVID-19. Br J Anaesth 2020;125(3):e309-e310.

92. Remy KE, Lin JC, Verhoef PA. High-flow nasal cannula may be no safer than non-invasive positive pressure ventilation for COVID-19 patients. Crit Care 2020;24(1):169.

93. England PH. Guidance on infection prevention and control for COVID-19. Sustained community transmission is occurring across the UK. Available at: https://www.gov.uk/government/publications/ wuhan-novel-coronavirus-infection-prevention-and-control\#summaryof-ppe-recommendations-for-health-and-social-care-workers. Accessed November 6, 2020
94. National Institutes of Health (NIH). COVID-19 Treatment Guidelines Panel. Coronavirus Disease 2019 (COVID-19) Treatment Guidelines. Date last updated: 11 February 11, 2021. Available at: https://www.covid19treatmentguidelines.nih.gov. Accessed November 6, 2020.

95. Harding H, Broom A, Broom J. Aerosol-generating procedures and infective risk to healthcare workers from SARS-CoV-2: the limits of the evidence. J Hosp Infect 2020;105(4):717-725.

96. Dhand R, Li J. Coughs and sneezes: their role in transmission of respiratory viral infections, including SARS-CoV-2. Am J Respir Crit Care Med 2020;202(5):651-659.

97. Ferioli M, Cisternino C, Leo V, Pisani L, Palange P, Nava S. Protecting healthcare workers from SARS-CoV-2 infection: practical indications. Eur Respir Rev 2020;29(155):200068.

98. Hui DS, Chow BK, Lo T, Tsang OTY, Ko FW, Ng SS, et al. Exhaled air dispersion during high-flow nasal cannula therapy versus CPAP via different masks. Eur Respir J 2019;53(4):1802339.

99. Roberts S, Kabaliuk N, Spence C, O’Donnell J, Zulkhairi Abidin Z, Dougherty R, et al. Nasal high-flow therapy and dispersion of nasal aerosols in an experimental setting. J Crit Care 2015;30(4):842.

100. Loh N-HW, Tan Y, Taculod J, Gorospe B, Teope AS, Somani J, Tan AYH. The impact of high-flow nasal cannula (HFNC) on coughing distance: implications on its use during the novel coronavirus disease outbreak. Can J Anaesth 2020;67(7):893-894.

101. Jermy MC, Spence CJT, Kirton R, O’Donnell JF, Kabaliuk N, Gaw $\mathrm{S}$, et al. Assessment of dispersion of airborne particles of oral/nasal fluid by high flow nasal cannula therapy. PLoS One 2021;16(2): e0246123.

102. Kotoda M, Hishiyama S, Mitsui K, Tanikawa T, Morikawa S, Takamino A, Matsukawa T. Assessment of the potential for pathogen dispersal during high-flow nasal therapy. J Hosp Infect 2020;104 (4):534-537.

103. Leung CCH, Joynt GM, Gomersall CD, Wong WT, Lee A, Ling L, et al. Comparison of high-flow nasal cannula versus oxygen face mask for environmental bacterial contamination in critically ill pneumonia patients: a randomized controlled crossover trial. J Hosp Infect 2019;101(1):84-87.

104. Li J, Fink JB, Ehrmann S. High-flow nasal cannula for COVID-19 patients: low risk of bio-aerosol dispersion. Eur Respir J 2020;55 (5):20000892.

105. Gaeckle NT, Lee J, Park Y, Kreykes G, Evans MD, Hogan CJ, Jr. Aerosol generation from the respiratory tract with various modes of oxygen delivery. Am J Respir Crit Care Med 2020;202(8):11151124.

106. He G, Han Y, Fang Q, Zhou J, Shen J, Li T, et al. Clinical experience of high-flow nasal cannula oxygen therapy in severe COVID-19 patients. Zhejiang Da Xue Xue Bao Yi Xue Ban 2020;49(2):232-239.

107. Leonard S, Atwood CW Jr, Walsh BK, DeBellis RJ, Dungan GC, Strasser W, Whittle JS. Preliminary findings on control of dispersion of aerosols and droplets during high-velocity nasal insufflation therapy using a simple surgical mask: implications for the high-flow nasal cannula. Chest 2020;158(3):1046-1049.

108. Montiel V, Robert A, Robert A, Nabaoui A, Marie T, Mestre NM, et al. Surgical mask on top of high-flow nasal cannula improves oxygenation in critically ill COVID-19 patients with hypoxemic respiratory failure. Ann Intensive Care 2020;10(1): 125.

109. Hamada S, Tanabe N, Inoue H, Hirai T. Wearing of medical mask over the high-flow nasal cannula for safer oxygen therapy in the COVID-19 era. Pulmonology 2021;27(2):171-173.

110. Li J, Fink JB, Elshafei AA, Stewart LM, Barbian HJ, Mirza SH, et al. Placing a mask on COVID-19 patients during high-flow nasal cannula therapy reduces aerosol particle dispersion. ERJ Open Res 2021;7(1):00519-2020. 


\section{HFNC AND COVID-19}

111. Raoof S, Nava S, Carpati C, Hill NS. High-flow, noninvasive ventilation and awake (nonintubation) proning in patients with coronavirus disease 2019 with respiratory failure. Chest 2020;158(5):1992-2002.

112. Arentz M, Yim E, Klaff L, Lokhandwala S, Riedo FX, Chong M, Lee M. Characteristics and outcomes of 21 critically ill patients with COVID-19 in Washington State. JAMA 2020;323(16):1612-1614.

113. Bhatraju PK, Ghassemieh BJ, Nichols M, Kim R, Jerome KR, Nalla AK, et al. Covid-19 in critically ill patients in the Seattle region case series. N Engl J Med 2020;382(21):2012-2022.

114. Chen T, Wu D, Chen H, Yan W, Yang D, Chen G, et al. Clinical characteristics of 113 deceased patients with coronavirus disease 2019: retrospective study. BMJ 2020;368:m1091.

115. Haudebourg AF, Perier F, Tuffet S, de Prost N, Razazi K, Mekontso Dessap A, Carteaux G. Respiratory mechanics of COVID-19 vs. Non-COVID-19 associated acute respiratory distress syndrome. Am J Respir Crit Care Med 2020;202(2):287-290.

116. Komorowski M, Aberegg SK. Using applied lung physiology to understand COVID-19 patterns. Br J Anaesth 2020;125(3):250-253.

117. Dhont S, Derom E, Van Braeckel E, Depuydt P, Lambrecht BN. The pathophysiology of 'happy' hypoxemia in COVID-19. Respir Res 2020;21(1):198.

118. Grieco DL, Menga LS, Eleuteri D, Antonelli M. Patient self-inflicted lung injury: implications for acute hypoxemic respiratory failure and ARDS patients on non-invasive support. Minerva Anestesiol 2019;85 (9):1014-1023.
119. Blez D, Soulier A, Bonnet F, Gayat E, Garnier M. Monitoring of high-flow nasal cannula for SARS-CoV-2 severe pneumonia: less is more, better look at respiratory rate. Intensive Care Med 2020;46 (11):2094-2095.

120. Coen M, Allali G, Adler D, Serratrice J. Hypoxemia in COVID-19; comment on: "the neuroinvasive potential of SARS - CoV2 may play a role in the respiratory failure of COVID-19 patients. J Med Virol 2020;92(10):1705-1706.

121. Zucman N, Mullaert J, Roux D, Roca O, Ricard J-D, Contributors. Prediction of outcome of nasal high flow use during COVID-19related acute hypoxemic respiratory failure. Intensive Care Med 2020;46(10):1924-1926.

122. Roca O, Caralt B, Messika J, Samper M, Sztrymf B, Hernández G, et al. An index combining respiratory rate and oxygenation to predict outcome of nasal high-flow therapy. Am J Respir Crit Care Med 2019;199(11):1368-1376.

123. Chandel A, Patolia S, Brown AW, Collins AC, Sahjwani D, Khangoora V, et al. High-flow nasal cannula in COVID-19: outcomes of application and examination of the ROX index to predict success. Respir Care 2021:66(6):909-919.

124. Tobin MJ. Basing respiratory management of COVID-19 on physiological principles. Am J Respir Crit Care Med 2020;201(11):13191320.

125. Wagner PD. The physiological basis of pulmonary gas exchange: implications for clinical interpretation of arterial blood gases. Eur Respir J 2015;45(1):227-243. 